\title{
A review on pesticide processing factors during processing of rice and barley based on CODEX
}

\author{
Jeong-Ah Kim ${ }^{1}$ Moo-Hyeog $\operatorname{Im}^{1}$
}

CODEX의 쌀과 보리에 대한 농약 가공계수 고찰

김정아 ${ }^{1} \cdot$ 임무혁 ${ }^{1}$

Received: 14 March 2019 / Accepted: 8 May 2019 / Published Online: 30 September 2019

(C) The Korean Society for Applied Biological Chemistry 2019

\begin{abstract}
This study summarized processing factor (PF) by the stage of rice and barley processing based on JMPR reports from 2006 to 2016. We compared PF of 17 pesticides in rice products during the processing of rice grain, husked rice, polished rice, hulls, bran and cooked rice. Among the 17 pesticides, 12 pesticides except for 5 pesticides such as acephate, methamidophos, glufosinate, quinclorac and sulfoxaflor mostly decreased in pesticides when rice grain processed into brown rice. Pesticides tended to be partially reduced when processed from husked rice to polished rice. However, hulls and bran produced during the milling process were concentrated. Acephate and others, 5 pesticides are systemic pesticides, and pesticides are penetrated into foods, and a large amount of pesticides was not removed during the milling process. The remaining pesticide residues in polished rice were mostly removed after processing into cooked rice, and trace amounts of pesticide residues remained. In the comparison of 23 pesticides PF during the processing of barley products (pearl barley, flour, short, malt, beer, hulls and bran). Most of the pesticide except for 4 pesticide (ethephon, pyraclostrobin, penthiopyrad, sulfoxaflor), which are systemic pesticides, decreased during the process of pearl barley production out of the barley grain. The pesticide in the malt, which was made by steeping pearl barley was concentrated

Moo-Hyeog $\operatorname{Im}(\varangle)$

E-mail:imh0119@daegu.ac.kr

${ }^{1}$ Department of Food Engineering, Daegu University, Gyeongbuk, Republic of Korea

This is an Open Access article distributed under the terms of the Creative Commons Attribution Non-Commercial License (http://creativecommons. org/licenses/by-nc/3.0/) which permits unrestricted non-commercial use, distribution, and reproduction in any medium, provided the original work is properly cited.
\end{abstract}

but when processed into beer, pesticide was remained only in trace amounts.

Keywords Barley - Codex Alimentarius Commission · Joint Meeting of the FAO Panel of Experts on Pesticide (JMPR) Pesticide Residue $\cdot$ Processing $\cdot$ Processing Factor $\cdot$ Rice

\section{서 론}

농약은 농작물의 재배저장운송 과정 중 해를 끼치는 병 - 해충 을 방제하는데 사용하고 있으며, 농산물의 품질향상, 노동력 절 감의 효과를 나타낸다. 그러나 농약은 자체 독성을 가지고 있 어 농약을 오 - 남용하여 생산된 농산물을 장기간 섭취하는 경 우 국민건강을 해칠 우려가 있다. 따라서 정부기관에서는 식품 의 잔류농약 안전관리를 위하여 국민이 평생 매일 섭취하여도 인체에 해를 끼치지 않는 수준의 농약잔류허용기준(Maximum Residue Limit, MRL)을 설정하여 관리하고 있다[1,3]. 농약 등 록 및 농약잔류허용기준 설정을 위해서 농약 회사 등에서는 농 약에 대한 급성, 아급성, 아만성, 만성 등의 독성 자료, 농산물 의 농약잔류자료, 식품 가공 중 농약 가공계수 자료 등을 정부 기관에 제출하여야 된다. 이러한 자료를 평가하여 농약의 일일 섭취허용량(Acceptable Daily Intake, $\mathrm{ADI}$ )을 설정하고 $\mathrm{ADI}$ 를 이용하여 식품 중 농약의 $\mathrm{MRL}$ 을 설정한다. 농민들은 농작물 재배 시 MRL이 설정된 농약을 사용할 수 있게 된다[4].

농산물 원료에 잔류된 농약은 조리, 가공 중 세척, 열 분해, 휘발 등으로 대부분 감소되지만, 잔류 농약 일부는 건조나 농 축과정 중에 원료보다 높게 잔류되기도 한다[5-14]. 우리나라의 경우, 잔류농약 기준을 건조농산물과 같이 조리·가공 중 농축 되는 경우에 농산물 원료와 건조농산물에 대하여 각각 기준설 
정을 한다[7-17]. 식품 중 농약의 MRL 설정 시 대부분의 경우 가공식품이 아닌 원료농산물에 대하여 제출된 농약 잔류자료로 부터 제안된 기준(안)과 국민 평균 식품섭취량을 이용하여 $\mathrm{ADI}$ 를 초과하지 않도록 농약기준치를 이론적인 섭취량 평가 (Theoretical Maximum Daily Intake, TMDI)를 통하여 설정하 고 있다[2,4]. 국제식품규격위원회 농약전문가위원회(Joint meeting FAO/WHO on Pesticides Residues, JMPR)에서는 원 료 농축 시, 우리나라와 같이 기준설정을 한다. 그러나 농산물 원료의 $\mathrm{MRL}$ 을 설정할 경우에는 기준(안)과 식품섭취량을 곱하 는 TMDI 평가 아닌 감독하의 잔류시험 중간 잔류값(Supervised Trial Medium Residue, STMR)과 식품 섭취량을 이용한 추정 섭취량(Estimated Daily Intake, EDI) 방식으로 위해 평가를 한 다. 우리나라는 농약의 $\mathrm{MRL}$ 설정 시 식품가공 중 농약이 감 소되거나 증가되는 가공계수를 사용하여 위해평가에 활용하고 있지 않으나, JMPR에서는 가공계수를 이용한 현실적인 위해평 가 방법을 활용하고 있다[18].

각국 정부 또는 농약회사 등에서는 Codex Alimentarius Commission $(\mathrm{CODEX})$ 에 농약 기준 설정을 위하여 식품 전처 리, 가공 - 조리 등의 과정 중 농약이 감소되거나 농축되는 공 정에 대한 연구를 수행하고 있다[18-19]. CODEX의 농약 가공 계수 연구 가이드라인에는 시료는 농약이 살포된 포장시험 현 장에서 채취되어야 하며, 가공 후에 대사물질이 생성된다면 이 들에 대한 고려도 필요하며, 동일한 가공절차 사용 시 특정 작 물에 대해 수행된 가공연구의 결과를 다른 작물군으로 외삽적 용이 가능하도록 되어있다[18]. JMPR 보고서 중 곡류에 대한 연구 자료 중 쌀은 현미, 백미, 밥, 쌀겨, 왕겨 등에 대한 농약 가공 연구, 보리는 통보리, 분말, 겨, 맥아, 맥주 등의 가공 중 농약 감소 연구가 있었다[34-71].

본 연구에서는 $\mathrm{CODEX}$ 농약 기준 설정을 위하여 JMPR에 제출된 연구자료 중 한국인의 섭취가 많은 쌀과 보리의 식품가 공방법과 가공방법에 따른 농약의 감소 및 증가 경향, 농약의 물리화학적 특성에 따른 가공계수 등을 분석하여 향후 농약가 공계수 연구의 기초자료로 활용하도록 하고자 한다.

\section{식품 가공 중 농약 가공계수 검토 및 정리 방법}

식품 가공 중 농약 연구자료는 $\mathrm{CODEX}$ 농약잔류허용기준 설 정을 위하여 JMPR에서 평가한 결과보고서 중 2006-2016년 자 료를 활용하였다. 식품 중 잔류농약의 가공계수(Processing Factor, PF)는 원료 농산물의 농약 잔류량에 대한 가공 후 식품 의 농약 잔류량의 비율을 나타낸 것이다.

Processing Factor $(\mathrm{PF})=$

Residue level in processed commodity $(\mathrm{mg} / \mathrm{kg})$

Residue level in RAC or commodity to be processed (mg/kg)
Table 1은 JMPR 보고서에서 조사한 농약의 종류를 각 농산물 별로 나타낸 표이다. JMPR에서 평가된 쌀의 acephate, azoxystrobin, chlorantraniliprole 등 17종 농약과 보리의 benzovindiflupyr, ethephon, fenitrothion 등 23종 농약에 대한 가공계수 연구를 조사하였다. Table 2 와 3 은 쌀과 보리에 사용된 농약의 분석방 법과 도정 및 가열 등의 가공방법에 대하여 정리하였다. 각 성 분 별로 식품의 잔류농약 분석 시 이용된 추출용매와 분석기기 에 대하여 Table 2와 같이 조사하였다[JMPR Evaluation 20062016]. 가공방법은 농작물 재배 중 농약을 살포한 시료를 이용 한 가공연구 결과를 조사하였다. 쌀은 벼를 수확 한 후 건조한 정조를 현미, 왕겨, 백미, 쌀겨와 쌀밥으로 가공되었다. 또한, 보 리는 정맥, 겉껍질, 분말, 겨, Shorts, 맥아와 맥주로 가공하는 과정 중 농약의 가공계수 자료를 조사하였다.

농작물에 잔류된 농약과 각 가공과정 중 농약 감소율의 상관 관계를 알아보기 위해, JMPR 보고서에서 평가된 농약 35종의 물리화학적 특성을 조사하였다. 농약의 지용성과 수용성을 나타 내는 옥탄올과 물 분배계수(Kow), 휘발성 또는 비휘발성을 판 단할 수 있는 증기압(vapor pressure), 농산물 표면에 잔류되거 나 중심부에 침투할 가능성을 판단할 수 있는 spectrum and route of action을 조사하였다[20].

\section{쌀과 보리 가공식품의 잔류농약 분석 방법}

잔류농약 분석방법은 쌀과 보리에 각 농약 별로 사용한 분석방 법을 요약하였다. Table 2는 JMPR에서 평가한 결과보고서의 농 약 성분 별로 가공된 식품 중 잔류농약 분석 시 전처리에 이용 된 추출용매와 $\mathrm{GC}$ 및 $\mathrm{GC}-\mathrm{MS}, \mathrm{LC}-\mathrm{MS} / \mathrm{MS}$ 등의 분석기기에 대하여 요약하였다.

Boscalid, fluxapyroxad, isopyrazam, sulfoxaflor 등 11종의 농약은 LC-MS/MS를 이용하여 분석하였다[34-71]. 보리에 잔류 된 quinoxyfen과 picoxystrobin은 $\mathrm{GC}-\mathrm{MS}$ 를 이용하여 분석하였 다. Fenitrothion, propiconazole, glufosinate와 quinclorac 등 7 종의 농약은 $\mathrm{GC}$ 를 이용하여 분석하였다[36-64].

$\mathrm{CODEX}$ 기준 설정을 위하여 JMPR에 제출된 쌀과 보리의 가공계수 연구 자료 중 농약은 총 20 종이었으며 총 22 건이였다. 이 중 $\mathrm{LC}-\mathrm{MS} / \mathrm{MS}$ 로 12 건, $\mathrm{GC}-\mathrm{MS}$ 로 2건, $\mathrm{GC}$ 로 8건 분석된 것으로 조사되었다. $\mathrm{LC}-\mathrm{MS} / \mathrm{MS}$ 로 분석한 비율이 총 22 건 중 12 건으로 $54.5 \%$ 를 차지하였다.

Zhiqiang 등[22]은 쌀의 가공과 저장에 따른 acephate와 methamidophos의 잔류량에 대한 연구를 수행하였으며, 시료를 acetonitrile로 추출하여 GC-FPD를 이용하여 분석하였다. Zhiqiang 등[23]의 보리와 맥주에 잔류된 triadimefon, malathion 과 dichlorvos의 분석은 acetonitrile로 추출한 후 LC-MS/MS를 이용하여 분석하였다. Uygun 등[24]은 malathion과 fenitrothion 을 처리한 보리의 저장, 맥아공정 중의 잔류량은 ethyl acetate

Table 1 Lists of rice and barley treated pesticides evaluated by JMPR

\begin{tabular}{cl}
\hline \hline Commodity & \multicolumn{1}{c}{ Pesticide } \\
\hline \multirow{2}{*}{ Rice } & Acephate, Azoxystrobin, Bentazone, Chlorantraniliprole, Chlorpyrifos-methyl, Cyhalothrin, Difenoconazole, Dichlorvos, \\
& Dinotefuran, Fenitrothion, Fluxapyroxad, Glufosinate, Methamidophos, Propiconazole, Quinclorac, Sulfoxaflor, Triazophos \\
\hline \multirow{3}{*}{ Barley } & $\begin{array}{l}\text { Azoxystrobin, Boscalid, Bixafen, Benzovindiflupyr, Chlorpyrifos-methyl, Cypermethrin, Ethephon, Fenitrothion, Flusilazole, } \\
\text { Fluxapyroxad, Flupyradifurone, Isopyrazam, Metrafenone, Pyraclostrobin, Penthiopyrad, Picoxystrobin, Pinoxaden, Quinoxyfen, } \\
\\
\text { Saflufenacil, Sulfoxaflor, Tebuconazole, Thiamethoxam, Trinexapac-ethyl }\end{array}$ \\
\hline
\end{tabular}


Table 2 Summary of analytical methods used for the determination of pesticides in barley, rice

\begin{tabular}{|c|c|c|c|c|}
\hline Pesticide & Commodity & Extraction solvents & Analysis Instrument & Reference \\
\hline Boscalid & Barley & methanol : water : hydrochloric acid & LC-MS/MS & 34 \\
\hline Quinoxyfen & Barley & acidic acetone & GC-MS & 35 \\
\hline \multirow{2}{*}{ Fenitrothion } & Barley & ethyl acetate & GC-FPD & \multirow{2}{*}{36} \\
\hline & Rice & ethyl acetate & GC-FPD & \\
\hline Propiconazole & Rice & & GC-ECD & 38 \\
\hline Acephate, Methamidophos & Rice & acetonitrile : water (70:5) & GC-FPD & 44 \\
\hline Isopyrazam & Barley & $\begin{array}{l}\text { acetonitrile : water ( } 50: 50 \text {, dry matrices such as } \\
\text { straw), acetonitrile : water ( } 80: 20 \text {, other crops) }\end{array}$ & LC-MS/MS & 45 \\
\hline Sulfoxaflor & Barley & & LC-MS/MS & 47 \\
\hline Pyraclostrobin & Barley & methanol : water $(70: 30)$ & LC-MS/MS & 46 \\
\hline Dinotefuran & Rice & acetonitrile : water $(8: 2)$ & LC-MS/MS & 50 \\
\hline \multirow{2}{*}{ Fluxapyroxad } & Barley & methanol : water $(50: 50)$ & LC-MS/MS & \multirow{2}{*}{51} \\
\hline & Rice & methanol : water $(50: 50)$ & LC-MS/MS & \\
\hline Glufosinate & Rice & & GC-FPD & 52 \\
\hline Picoxystrobin & Barley & acetonitrile : water $(9: 1)$ & GC-MS & 53 \\
\hline Bixafen & Barley & acetonitrile : water ( $4: 1$, using microwaves) & LC-MS/MS & 56 \\
\hline Triazophos & Rice & acetone & GC-FPD & 60 \\
\hline Trinexapac-ethyl & Barley & acetonitrile : $1 \mathrm{~N}$ hydrochloric acid $(80: 20)$ & LC-MS/MS & 61 \\
\hline Ethephon & Barley & methanol & GC-FPD & 63 \\
\hline Quinclorac & Rice & acetone : $0.1 \mathrm{M} \mathrm{NaOH}(10: 15)$ & GC-ECD & 64 \\
\hline Flupyradifurone & Barley & acetonitrile : water $(4: 1)$ & LC-MS/MS & 66 \\
\hline Pinoxaden & Barley & $1 \mathrm{~N} \mathrm{HCl}$ : acetonitrile $(90: 10)$ & LC-MS/MS & 68 \\
\hline Saflufenacil & Barley & & LC-MS/MS & 69 \\
\hline
\end{tabular}

에 anhydrous sodium sulphate를 첨가하여 추출한 후 GC-NPD 로 분석한 것으로 조사되었다. 농산물과 가공 식품 중 농약의 분석은 농약의 물리화학적 특성에 따라 다양한 기기로 분석한 것으로 조사되었다.

\section{쌀과 보리의 식품 가공 방법}

Table 3은 JMPR의 쌀과 보리에 대한 농약의 가공계수 연구에 서 가공 방법에 대하여 요약하였다. 쌀의 가공은 정조, 현미, 왕 겨, 백미, 쌀겨, 현미밥, 쌀밥에 대하여, 보리의 가공은 정맥, 겉 껍질, 분말, 겨, short, 맥아, 맥주에 대하여 수행된 것으로 조사 되었다.

쌀의 일반적인 가공과정은 벼(정조)로부터 이물을 제거하는 정선공정을 거친 후 탈각기를 이용하여 왕겨를 제거하여 현미 를 만들고 현미를 도정하여 쌀겨층을 벗겨내어 백미를 만든다 [25]. JMPR 보고서 중 현미의 가공방법은 수확한 벼를 건조시 키고, 흡인, 선별과정을 거쳐 알곡 분획물 등의 찌꺼기를 제거 하고 탈피과정을 거쳐 왕겨를 벗겨낸다[JMPR 2007]. 백미의 가 공은 쌀겨의 총량이 현미 무게의 $11-17 \%$ 가 되도록 현미를 백 미로 도정한다[JMPR 2008, 2012]. 쌀겨는 현미를 백미로 도정 하는 과정에서 발생한다[JMPR 2008]. JMPR에 제출된 쌀의 가 공방법[JMPR 2007, 2008, 2012]과 일반적인 쌀의 가공 과정을 설명한 대학 교재[25]의 가공방법과 유사한 것으로 조사되었다.

보리의 일반적인 가공방법은 정맥의 경우 건조시켜 흡인, 선 별한 후 탈피시켜 겨를 제거한 것이다[26]. 맥아는 보리를 1-2
일 동안 물에 침지시킨 후 4 8일정도 발아시켜 녹맥아 상태로 제조한다. 이 녹맥아를 $50 \sim 90{ }^{\circ} \mathrm{C}$ 까지 열풍건조를 시켜 분쇄한 다[26]. JMPR에 제출된 보리의 가공방법은 보리를 건조, 선별, 흡인하여 껍질을 벗긴 정맥[49-53]을 선별하여 침지시킨 후 발 아시킨다. 그 후 배조한 것을 맥아로 하였다[49-53]. 보리를 이 용한 맥주의 일반적인 가공 방법은 보리를 정선하여 제맥의 품 질을 균일하게 한 후 침맥, 발아, 배조의 단계를 거쳐 맥아를 만든다. 맥아를 후숙, 분쇄하여 물과 부원료를 혼합하여 담금, 여과하여 만든 맥아즙에 호프를 첨가하여 열처리를 한 후 효모 를 첨가하여 발효과정을 거친다. 미숙성맥주(young beer)를 후 숙, 여과하여 맥주를 제조한다[26]. JMPR 보고서에서 조사된 맥주 가공방법은 맥아를 으깨고 물을 첨가하여 맥아즙을 만든 다. 이 맥아즙을 lautering을 통해서 곡물 찌꺼기를 제거하고 호 프를 첨가한 후 가열한다. 그리고 효모를 첨가하여 발효 시킨 후 여과하여 맥주를 제조하는 것으로 조사되었다[42,49-53].

\section{쌀의 가공과정 중 잔류농약 가공계수 고찰}

Codex에 농약잔류허용기준 설정을 위하여 제출된 자료 중 쌀에 대한 PF 연구자료를 가공방법 별로 정리하여 비교한 결과를 Table 4에 나타내었다. 농약과 각 가공과정의 상관관계를 알아 보기 위해, JMPR 보고서에서 평가된 농약 17 종의 분배계수 (Kow), 증기압, spectrum and route of action을 조사하였다.

벼를 수확하여 건조한 정조의 가공계수를 1 로 정한 다음, 정 조의 껍질을 제거한 현미의 $\mathrm{PF}$ 는 0.06-1, 왕겨의 $\mathrm{PF}$ 는 2.1-10 
Table 3 General processing methods of Cereals

\begin{tabular}{|c|c|c|c|}
\hline Commodity & product & processing method & Reference \\
\hline \multirow{4}{*}{ Rice } & Husked rice & Drying (43-60 ${ }^{\circ} \mathrm{C}, 11-14 \%$ )-aspirating-screening-dehulling-separating hulls & $36-38$ \\
\hline & Polished rice & $\begin{array}{l}\text { Husked rice-milling-screening-separating bran (The process was repeated until the total amount of } \\
\text { bran was } 11-17 \% \text { of the starting husked rice weight.) }\end{array}$ & $39-41,49-53$ \\
\hline & Bran & $\begin{array}{l}\text { Husked rice-milling-screening-separating polished rice (The process was repeated until the total } \\
\text { amount of bran was } 11-17 \% \text { of the starting husked rice weight.) }\end{array}$ & $39-41,49-53$ \\
\hline & Hulls & Drying $\left(43-60{ }^{\circ} \mathrm{C}, 11-14 \%\right)$-aspirating-screening-dehulling-separating husked rice & $36-38$ \\
\hline \multirow{7}{*}{ Barley } & Beer & $\begin{array}{l}\text { Malt-crushing-mashing (add water)-lautering-boiling (add hop)-whirlpool-fermentation (add yeast)- } \\
\text { filtering-bottling }\end{array}$ & $42,49-53$ \\
\hline & Pearly barley & Drying-screening-aspirating-dehulling-separating from hulls & $49-61$ \\
\hline & Flour & Pearly barley-milling & $49-53$ \\
\hline & Shorts & Pearly barley-milling-screening-sifting & $49-61$ \\
\hline & Malt & Pearly barley-screening-steeping-germinating-kilning & $49-53$ \\
\hline & Hulls & Drying-screening-aspirating-dehulling-separating from grains & $49-53$ \\
\hline & Bran & Pearly barley-milling-screening-sifting & $49-53$ \\
\hline
\end{tabular}

${ }^{1)}$ AGF: Aspirated Grain Fraction

로 조사되었다. 현미를 도정한 백미의 $\mathrm{PF}$ 는 $0.01-0.63$ 로 대부분 의 경우 많은 양의 농약 성분이 제거됨을 알 수 있었다. 백미 로 도정과정 중 발생된 부산물인 쌀겨의 $\mathrm{PF}$ 는 0.15-7.2로 농약 이 농축되는 경향이었다. 백미를 가열한 쌀밥의 PF는 0.006-0.04 로 대부분의 농약 성분이 감소되는 것으로 조사되었다[JMPR 2007, 2008, 2011, 2012, 2013, 2015, 2016]. 쌀의 가공방법에 따라 농약 별 $\mathrm{PF}$ 를 비교한 결과, acephate, glufosinate, methamidophos, quinclorac, sulfoxaflor 5종 농약을 제외한 농약 12 종 중 chlorpyrifos-methyl, difenoconazole, dichlorvos, fluxapyroxad, triazophos 5 종은 정조를 현미로 가공하였으며, 이 과정에서 $\mathrm{PF}$ 가 각각 $0.22,0.06,0.16,0.13$ 과 0.24 로 조사되었고, 농약의 감소율은 각각 $78,94,84,87$ 및 $76 \%$ 로 평균 $83.8 \%$ 감소되 는 경향을 보였다[JMPR 2013, 2015, 2012]. 이들 결과는 농약 이 살포된 정조의 표면에 농약이 가장 많이 잔류되어 있으므로, 왕겨를 탈피하는 과정에서 농약이 대부분 제거되는 것으로 판 단된다. 이들 12 종의 농약은 현미를 백미로 도정하는 공정에서 현미 PF가 0.06-1에서 백미로 도정한 후 0.005-0.19로 감소되어 $66.7-99 \%$ 의 농약 감소율을 보였다[JMPR 2008, 2013, 2015, 2012, 2007]. 현미에서 백미로 도정하는 과정에서 평균 $85.4 \%$ 의 농약 성분이 제거되어서 잔류된 농약의 상당부분은 백미로 가공할 경우 대부분 제거됨을 알 수 있었다.

JMPR 보고서의 쌀에 대한 17종 농약 중 difenoconazole 농 약의 쌀에 대한 가공연구는 정조, 현미, 왕겨, 백미, 쌀겨, 쌀밥, 현미 parboiled rice, 백미 parboiled rice의 전체 공정을 수행하 여 쌀의 가공연구를 대표할 수 있을 것으로 판단되었다. Difenoconazole의 PF는 정조 1 , 현미 0.06 , 왕겨는 4.05 , 백미 0.01 , 쌀겨는 0.15 , 쌀밥은 0.006 , parboiled rice의 현미는 0.41 , parboiled rice의 백미는 0.23 으로 조사되었다[JMPR 2015]. 정 조를 현미로 가공하여 PF가 1 에서 0.06 으로 0.94 가 제거되어 농약이 $94 \%$ 로 많은 양이 감소되었으며, 현미를 백미로 도정하 는 과정으로 0.06 에서 0.01 로 0.05 의 $\mathrm{PF}$ 가 제거되어 $83.3 \%$ 의 감소율을 보였다. 백미를 쌀밥으로 가공한 후 $\mathrm{PF}$ 는 0.01 에서 0.006 으로 $40 \%$ 감소되었다. Parboiled rice는 물에 4 6시간 침 지시킨 후 $100^{\circ} \mathrm{C}$ 에서 가열하여 $18 \sim 35^{\circ} \mathrm{C}$ 에서 건조시켜 벼의
수분함량 $30 \%$ 에서 parboiled rice는 최종 12 14\%정도로 건조 된다. 건조된 parboiled rice는 왕겨를 벗겨내 현미로 가공하고, 이 현미를 도정하여 백미로 가공한다(25, JMPR 2015). 물에 침 지시킨 후 벼를 높은 온도로 쪄서 건조시킨 parboiled rice의 $\mathrm{PF}$ 는 현미에서 0.41 , 백미에서 0.23 으로 조사되어 일반 현미의 $\mathrm{PF} 0.06$, 일반 백미 0.01 에 비해서 농약의 가공계수가 높은 것 으로 조사되었다. Parboiled rice는 벼를 찌는 과정에서 왕겨와 현미층에 있는 영양물질이 쌀 내부로 흡수하고 건조를 통해 수 분함량이 감소하고 영양분이 농축된다[30]. 이 과정에서 잔류된 농약 성분도 쌀의 내부로 이동하였기 때문에 parboiled rice가 가열처리과정이 추가되었음에도 불구하고 일반 현미, 백미의 $\mathrm{PF}$ 보다 높은 것으로 판단되었다. Difenoconazole의 증기압은 $3.3 \times 10^{-5} \mathrm{mPa}\left(25^{\circ} \mathrm{C}\right)$, Kow 4.4 로 휘발성이 낮고 지용성이며, 내부로 침투하는 침투성 농약임에도 불구하고 도정과 가열과정 에서 농약 성분이 $94,83.3$ 및 $40 \%$ 감소되어 대부분 분해되어 감소되는 경향을 보였다[20]. Zhibo 등이 연구[32]한 동부콩의 difenoconazole 가공연구에서 $100^{\circ} \mathrm{C}$ 에서 3 분간 열처리한 결과, $\mathrm{PF}$ 는 0.24 로 보고하였다. 이 결과는, JMPR 보고서에 나타난 쌀 에 가공계수 연구와 유사한 결과로 difenoconazole 농약은 가열 에 의하여 감소는 경향을 보였다.

쌀밥에 대한 가공연구는 chlorpyrifos-methyl, difenoconazole, fenitrothion 3종의 농약에 대해서 조사되었다[JMPR 2013, 2015, 2007]. 백미를 쌀밥으로 가공한 PF가 chlorpyrifos-methyl 은 0.034 에서 0.012 , difenoconazole은 0.01 에서 0.006 , fenitrothion 은 0.15 에서 0.04 로 각각 $64.7,40$ 및 $73.3 \%$ 의 농약이 감소되 었다. 농약성분이 백미에서 잔류되어도 쌀밥 가공 과정 중 열 에 의해 대부분의 잔류농약이 분해되어 미량만 잔류되는 것을 알 수 있었다. Lee등의 백미 가공을 통한 chlorpyrifos 잔류량 변화에 대한 연구[31]에서 백미를 쌀밥으로 가공하였을 때 잔 류량이 $456 \mathrm{ppb}$ 에서 $130.5 \mathrm{ppb}$ 로 감소하는 결과를 보였다. 이를 $\mathrm{PF}$ 로 산출하여 비교하였을 때 0.286 으로 $71.4 \%$ 감소하여 $\mathrm{JMPR}$ 에서 진행한 쌀밥에 대한 가공연구와 유사한 결과를 나타 내었다.

쌀에 대한 가공연구가 수행된 농약 총 17 종 중 acephate, 
Table 4 Processing factor of residue pesticides for rice

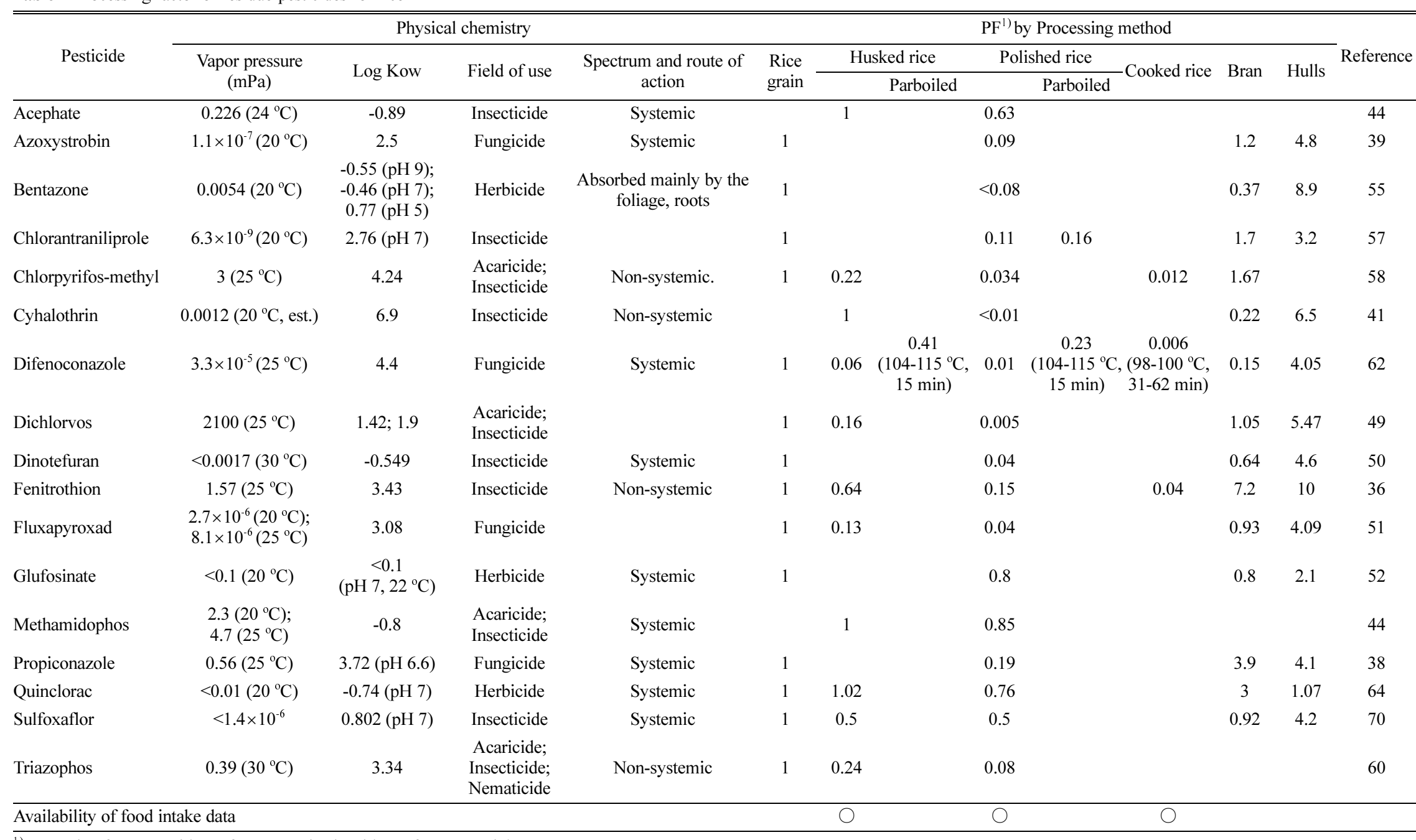


methamidophos, glufosinate, quinclorac, sulfoxaflor 5종 농약은 일반적인 농약 가공 연구 결과의 경향과 상이하였다. 현미에서 백미로 가공 연구 결과, acephate와 대사물질인 methamidophos 의 잔류량에 대한 $\mathrm{PF}$ 는 각각 1 에서 $0.63,1$ 에서 0.85 로 $37 \%$ 와 $15 \%$ 로 감소되었다. Acephate의 증기압은 $0.226 \mathrm{mPa}\left(24^{\circ} \mathrm{C}\right)$, Kow는 -0.89 이고, methamidophos의 증기압은 $2.3 \mathrm{mPa}\left(20^{\circ} \mathrm{C}\right)$, $4.7 \mathrm{mPa}\left(25^{\circ} \mathrm{C}\right), \mathrm{Kow}$ 는 -0.8 로 휘발성이 높고 수용성이며 내 부로 침투하는 침투성 농약이므로 다른 농약에 비해서 가공 후 잔류농약 감소율이 낮은 것으로 판단된다[20]. Xiao 등은 쌀을 현미, 백미, 겨, 왕겨로 가공하여 acephate의 잔류량을 비교한 연구를 수행하였으며, 정조 $3.71 \mathrm{mg} / \mathrm{kg}$ 에서 현미로 가공하여 $0.92 \mathrm{mg} / \mathrm{kg}$ 을 나타내었고, 현미에서 백미로 가공하여 $0.51 \mathrm{mg}$ $\mathrm{kg}$ 으로 감소하는 결과를 보였다[22]. 이를 $\mathrm{PF}$ 로 산출하면, 정조 1 , 현미 0.24 , 백미 0.14 로 정조에서 현미로 가공할 때 $76 \%$, 현 미를 백미로 가공할 때 $41.7 \%$ 감소하였다. JMPR 보고서 중 현미에서 백미로 가공할 때 acephate와 methamidophos의 감소 율과 비슷한 경향을 나타내었다.

Glufosinate 농약의 감소계수 연구에서는 정조에서 백미로만 가공하였다. 정조의 $\mathrm{PF} 1$ 에서 백미는 0.8 로 조사되어, 농약 감 소율은 $20 \%$ 를 보였다. Glufosinate의 증기압은 $<0.01 \mathrm{mPa}$ $\left(20{ }^{\circ} \mathrm{C}\right)$ 이고 $\mathrm{Kow}$ 는 $\mathrm{pH} 7,22{ }^{\circ} \mathrm{C}$ 에서 $<0.1$ 로 수용성 농약이며 침투성 농약이다[20]. 정조를 탈피와 도정과정을 거쳐 백미로 가공하였지만 glufosinate는 침투성 농약이므로 쌀의 중심부로 침투된 것으로 판단된다. 정조를 백미로 가공한 후 농약이 $20 \%$ 감소하였지만, $80 \%$ 는 백미에 잔류되어 제거되지 않은 것으로 조사되었다.

Quinclorac은 정조를 현미로 가공할 때 PF가 1에서 1.02로 조사되었으며, 현미를 백미로 도정과정에서 현미 1.02 에서 0.76 으로 $25.5 \%$ 감소하였다[JMPR 2015]. Quinclorac은 $<0.1 \mathrm{mPa}$ $\left(20^{\circ} \mathrm{C}\right)$ 의 증기압, $\mathrm{pH}$ 7에서 -0.74 의 Kow로, 휘발성이 낮고, 수용성이며 침투성 농약으로 조사되었다[20]. 이 농약은 내부로 침투하는 성분이므로 백미로 도정 시, $25.5 \%$ 의 낮은 감소율을 보였다.

Sulfoxaflor는 정조에서 현미로 가공할 때 $\mathrm{PF}$ 가 1 에서 0.5 로 $50 \%$ 감소하였으나, 현미를 백미 도정 후에 $\mathrm{PF}$ 가 0.5 로 변화가 없는 것으로 조사되었다[JMPR 2016]. Sulfoxaflor는 증기압이 $<1.4 \times 10^{-6} \mathrm{mPa}$, Kow가 $\mathrm{pH}$ 7에서 0.802 로 휘발성이 낮고, 수 용성이며 침투성 농약[20]이므로 백미로 도정 후에도 농약의 감 소율이 낮은 것으로 판단된다. 2011년 JMPR 보고서의 감자에 대한 가공계수 연구에서 sulfoxaflor는 감자를 박피할 때 $\mathrm{PF}$ 가 1 에서 1.6 으로 농축되는 결과를 나타내었다. 감자의 껍질을 제 거하였지만 농약성분이 감소되지 않은 것이 쌀과 유사한 결과 를 나타내었다[JMPR 2011].

쌀에 대해서 가공연구가 수행된 농약 총 17 종 중 azoxystrobin, bentazone, chlorantraniliprole, chlorpyrifos-methyl, cyhalothrin 등 12 종은 도정과정 중에 정조에 잔류된 농약성분의 상당량이 감소하는 경향이었다. 정조에서 현미로 가공할 때 대부분의 농 약이 감소하였고, 현미에서 백미로 가공 할 때 일부 감소하는 경향을 보였다. 그러나 침투성농약인 acephate, methamidophos, glufosinate, quinclorac, sulfoxaflor 5종 농약은 농약 성분이 내 부로 침투되어 도정공정 중에 많은 양이 제거되지 않는 것으로 나타났다. 일반적인 경우 침투성 농약은 농약성분이 내부로 침
투되어 도정과정 중에 감소량이 낮은 것으로 예상되고, 비침투 성 농약은 표면에 잔류되어 상당량이 감소하는 것으로 예상된 다. 그러나 JMPR 보고서를 조사한 결과, 총 17 종 중 침투성 농약은 acephate, azoxystrobin, bentazone, difenoconazole, dinotefuran, glufosinate, methamidophos, propiconazole, quinclorac, sulfoxaflor, triazophos 11종이었으나, 이 중 acephate, methamidophos, glufosinate, quinclorac, sulfoxaflor의 5종의 가공연구 결과는 농약이 내부로 침투되어 농약의 낮은 감소율 결과를 나타내어 침투성 농약의 일반적인 경향을 보였다. 그러나 azoxystrobin, bentazone, difenoconazole, dinotefuran, propiconazole, triazophos 6종 농 약은 침투성이지만 일반적인 경향이 아닌 높은 감소율의 결과 로 조사되었다. 이러한 경향은 농약의 일반적인 물리화학적 특 성에 따라 농약의 잔류량이 유의적인 상관관계를 보이지 않은 것으로 조사되어 $\mathrm{Im}$ 과 $\mathrm{Ji}$ 의 과일류에 대한 가공계수 연구와 유 사한 결과를 나타내었다[28].

JMPR에 제출된 쌀에 대한 총 17 종의 농약 중 쌀밥에 대한 가공연구는 3종에 불가하였다[JMPR 2007, 2013, 2015]. JMPR 보고서에는 우리나라의 주식인 쌀밥에 대한 연구자료가 부족하 여 향후 우리나라에서 쌀에 대한 PF 연구 시 쌀밥에 대한 가 공연구가 활발하게 진행될 필요가 있을 것으로 판단된다.

\section{보리의 가공과정 중 잔류농약 가공계수 고찰}

Table 5는 보리에 대한 23종 농약의 통보리, 정맥, 겉껍질, 분 말, 겨, short, 맥아, 맥주의 $\mathrm{PF}$ 연구자료를 가공방법 별로 정리 하였다. Table 5는 23종 농약의 Kow, 증기압, 침투이행성 여부 의 특성을 조사한 결과이다. 보리를 수확하여 건조한 통보리의 $\mathrm{PF} 1$ 을 기준으로 하여 가공방법 별 $\mathrm{PF}$ 를 조사하였다. 통보리의 껍질을 제거한 정맥의 $\mathrm{PF}$ 는 1에서 0.12-1.2로 탈피과정으로 상 당량의 농약이 감소되었고, 이 과정에 발생한 겉껍질의 경우 1.6-2로 농약 성분이 농축되었다. 정맥 0.12-1.2에서 분쇄하여 제 조한 분말의 $\mathrm{PF}$ 는 $0.097-0.8$ 로 소폭 감소하는 결과를 보였고, 이 과정에서 부산물로 발생된 겨의 $\mathrm{PF}$ 는 0.39-7.8로 농약 성분 이 농축되었다. 정맥 0.12-1.2에서 침지하여 발아시킨 맥아의 $\mathrm{PF}$ 는 0.01-1.3으로 조사되었다. 맥아를 발효시킨 맥주에서는 0.0010.67 로 대부분의 농약이 분해되거나 희석되어 미량의 성분만이 잔류되었다[JMPR 2013, 2006, 2016, 2009, 2008, 2015, $2007,2012,2011,2010]$. 보리의 가공방법에 따라 농약의 $\mathrm{PF}$ 를 비교한 결과, ethephon, pyraclostrobin, penthiopyrad, sulfoxaflor, trinexapac-ethyl을 제외한 11종의 농약은 통보리를 건조, 선별, 흡인하여 연삭이나 마찰로 보리의 겨층이 제거하여 정맥으로 만 드는 과정으로 $\mathrm{PF}$ 가 1에서 0.092-0.48로 농약성분이 상당량 감 소되어, 농약 감소율이 $54-90.8 \%$ 로 평균 $73.5 \%$ 로 대부분의 농 약이 감소되었다[2006, 2013, 2016, 2012, 2011, 2010]. 이는 보리 재배에 사용된 농약이 통보리의 겉껍질에 농약 성분이 가 장 많이 잔류되어 있으므로 겨층을 제거하는 과정에서 대부분 제거되는 것으로 판단된다. JMPR 보고서의 토마토에 대한 가 공계수 연구에서 fluxapyroxad는 박피과정을 통하여 잔류량이 $92 \%$ 감소되었으며[JMPR 2012], 보리의 탈피과정에서 fluxapyroxad는 PF가 1 에서 0.16 으로 $84 \%$ 의 농약이 감소되었다. JMPR 보고서에 조사된 토마토와 보리의 가공과정 중 fluxapyroxad 잔류량을 비교한 결과, 농산물의 종류가 달라도 탈피 또는 박 피 과정에서 농약이 대부분 제거되는 유사한 경향을 나타내었다. 
Table 5 Processing factor of residue pesticides for barley

\begin{tabular}{|c|c|c|c|c|c|c|c|c|c|c|c|c|c|}
\hline \multirow[b]{2}{*}{ Pesticide } & \multicolumn{4}{|c|}{ Physical chemistry } & \multicolumn{8}{|c|}{$\mathrm{PF}^{1)}$ by Processing method } & \multirow[b]{2}{*}{ Reference } \\
\hline & $\begin{array}{c}\text { Vapor Pressure } \\
(\mathrm{mPa})\end{array}$ & Log Kow & Field of use & Spectrum and route of action & $\begin{array}{c}\text { Barley } \\
\text { grain }\end{array}$ & $\begin{array}{c}\text { Pearl } \\
\text { barley }\end{array}$ & Beer & Flour & Shorts & Malt & Hulls & Bran & \\
\hline Azoxystrobin & $1.1 \times 10^{-7}\left(20^{\circ} \mathrm{C}\right)$ & 2.5 & Fungicide & systemic & 1 & & 0.03 & & & 0.1 & & & 54 \\
\hline Boscalid & $0.00072\left(20^{\circ} \mathrm{C}\right)$ & 2.96 & Insecticide & systemic & 1 & 0.33 & 0.02 & & & 0.93 & & 7.8 & 34 \\
\hline Bixafen & $4.6 \times 10^{-5}\left(20^{\circ} \mathrm{C}\right)$ & 3.3 & Fungicide & systemic & 1 & 0.22 & $<0.065$ & & & 0.86 & & & 56 \\
\hline Benzovindiflupyr & $3.2 \times 10^{-6}\left(25^{\circ} \mathrm{C}\right)$ & 4.3 & Fungicide & & 1 & 0.46 & & 0.4 & & & & 0.39 & 65 \\
\hline Chlorpyrifos-methyl & $3\left(25^{\circ} \mathrm{C}\right)$ & 4.24 & Acaricide; Insecticide & Non-systemic & 1 & & $<0.001$ & & & & & & 42 \\
\hline Cypermethrin & $0.0002\left(20^{\circ} \mathrm{C}\right)$ & 6.6 & Insecticide & Non-systemic & 1 & & $<0.03$ & & & & & & 41 \\
\hline Ethephon & $<0.01\left(20^{\circ} \mathrm{C}\right)$ & $<-2.2$ & Plant growth regulator & Systemic & 1 & 0.9 & & & & & 1.6 & & 63 \\
\hline Fenitrothion & $1.57\left(25^{\circ} \mathrm{C}\right)$ & 3.43 & Insecticide & Non-systemic & & & & & & 0.2 & & & 36 \\
\hline Flusilazole & $0.039\left(25^{\circ} \mathrm{C}\right)$ & $3.74(\mathrm{pH} 7)$ & Fungicide & Systemic & 1 & & & 0.45 & 0.51 & & 2 & 0.68 & 37 \\
\hline Fluxapyroxad & $\begin{array}{l}2.7 \times 10^{-6}\left(20^{\circ} \mathrm{C}\right) \\
8.1 \times 10^{-6}\left(25^{\circ} \mathrm{C}\right)\end{array}$ & 3.08 & Fungicide & & 1 & 0.16 & 0.02 & 0.15 & & & & 1.89 & 51 \\
\hline Flupyradifurone & $9.1 \times 10^{-7}\left(20^{\circ} \mathrm{C}\right)$ & 0.3 & Insecticide & systemic & 1 & 0.12 & 0.075 & & & 0.49 & & & 66 \\
\hline Isopyrazam & & & Fungicide & & 1 & 0.37 & $<0.13$ & & & 0.55 & & & 45 \\
\hline Metrafenone & $\begin{array}{l}0.153\left(20^{\circ} \mathrm{C}\right) \\
0.256\left(25^{\circ} \mathrm{C}\right)\end{array}$ & $4.3(\mathrm{pH} 4.0)$ & Fungicide & systemic & 1 & 0.165 & $<0.15$ & & & 0.4 & & & 67 \\
\hline Pyraclostrobin & $2.6 \times 10^{-5}\left(20^{\circ} \mathrm{C}\right)$ & 3.99 & Fungicide & & 1 & $<0.67$ & $<0.67$ & & & 1.17 & & & 46 \\
\hline Penthiopyrad & $0.00643\left(25^{\circ} \mathrm{C}\right)$ & & Fungicide & systemic & 1 & 0.68 & $<0.24$ & & & & & & 59 \\
\hline Picoxystrobin & $0.0055\left(20^{\circ} \mathrm{C}\right)$ & 3.6 & Fungicide & Systemic & 1 & & 0.26 & & & & & & 53 \\
\hline Pinoxaden & $\begin{array}{l}0.0002\left(20^{\circ} \mathrm{C}\right) \\
0.00046\left(25^{\circ} \mathrm{C}\right)\end{array}$ & 3.2 & Herbicide & Systemic & 1 & 0.48 & 0.13 & 0.46 & & 1.17 & & 1.71 & 68 \\
\hline Quinoxyfen & $\begin{array}{c}0.012\left(20^{\circ} \mathrm{C}\right) \\
0.02\left(25^{\circ} \mathrm{C}\right)\end{array}$ & 4.66 (pH c. 6.6) & Fungicide & Systemic & 1 & & 0.1 & & & 0.5 & & & 35 \\
\hline Saflufenacil & $4.5 \times 10^{-12}\left(20^{\circ} \mathrm{C}\right)$ & 2.6 & Herbicide & $\begin{array}{l}\text { Absorbed by foliage and roots, } \\
\text { with translocation in the } \\
\text { apoplast and limited } \\
\text { movement in the phloem }\end{array}$ & 1 & 0.092 & 0.098 & 0.097 & & & & 2.9 & 69 \\
\hline Sulfoxaflor & $<1.4 \times 10^{-6}$ & $0.802(\mathrm{pH} 7)$ & Insecticide & systemic & 1 & 0.7 & 0.2 & 0.8 & & 1.3 & & 1.0 & 47 \\
\hline Tebuconazole & $0.0017\left(20^{\circ} \mathrm{C}\right)$ & 3.7 & Fungicide & Systemic & 1 & 0.27 & $<0.025$ & & & 1 & & & 48 \\
\hline Thiamethoxam & $6.6 \times 10^{-6}\left(25^{\circ} \mathrm{C}\right)$ & -0.13 & Insecticide & Systemic & 1 & 0.25 & & 0.08 & & & & & 43 \\
\hline Trinexapac-ethyl & $2.16\left(25^{\circ} \mathrm{C}\right)$ & $\begin{array}{c}-2.1 \text { (pH 8.9); } \\
-0.29 \text { (pH 6.9); } \\
1.5 \text { (pH 5) }\end{array}$ & Plant growth regulator & & 1 & 1.2 & & 0.43 & & & & 1.9 & 61 \\
\hline
\end{tabular}


정맥을 분쇄하여 가공한 분말에 대한 연구는 benzovindiflupyr, flusilazole, fluxapyroxad, pinoxaden, saflufenacil, sulfoxaflor, thiamethoxam, trinexapac-ethyl의 8종의 농약에서 수행되었다 [JMPR 2016, 2007, 2012, 2011，2010， 2013]. 그 중 flusilazole, thiamethoxam, trinexapac-ethyl의 보리 알곡의 $\mathrm{PF}$ 는 1 에서 각각 $0.45,0.08$ 및 0.43 로 감소하여 55,92 및 $57 \%$ 의 감소율을 나타내었다. Benzovindiflupyr, fluxapyroxad, pinoxaden 의 보리 알곡의 $\mathrm{PF}$ 는 1 , 정맥의 $\mathrm{PF}$ 는 $0.46,0.16$ 및 0.48 로 나타나 감소율은 $54,84,52 \%$ 로 조사되었으며, 분말로 가공 후 에는 PF가 각각 0.4, 0.15 및 0.46로 조사되었다. Benzovindiflupyr, fluxapyroxad, pinoxaden는 정맥에서 분말로 분쇄과정 중에는 농 약이 거의 감소되지 않은 것으로 조사되었다[20].

Saflufenacil은 $\mathrm{PF}$ 는 보리 알곡 1 , 정맥 0.092 , 분말 0.097 로 정맥으로 껍질이 제거되는 가공과정에서 대부분의 농약이 제거 되었으나, sulfoxaflor은 보리 알곡 1 , 정맥 0.7 , 분말 0.8 으로 조사되어 껍질 제거과정에서 $30 \%$ 정도 제거되었다. Park 등의 밀의 제분에 따른 밀가루 중 농약 가공계수 산출연구[33]에서 azinphos-methyl, chlorpyrifos-methyl이 0.05 , chlorpyrifos, trichlorfon 이 0.06 , fenitrothion, malathion이 0.07 로 산출되어 원곡인 통 밀에 잔류된 농약은 제분을 통해 밀가루로 가공될 경우 5 7\% 가 정도가 남아 있는 것으로 나타났다. JMPR 보고서에서 보리 제분 공정 중 benzovindiflupyr, flusilazole, fluxapyroxad, pinoxaden, saflufenacil, sulfoxaflor, thiamethoxam, trinexapacethyl의 PF는 $0.4,0.15,0.45,0.46,0.097,0.8,0.08,0.43$ 으로 보리 알곡에 잔류된 농약은 제분을 통해 분말로 가공될 경우 많은 양의 농약 성분이 감소하는 비슷한 경향을 보였다.

9종 농약에 대하여 정맥을 맥아를 제조하여 $\mathrm{PF}$ 를 산출한 결 과, boscalid는 0.33 에서 0.93 , bixafen 0.22 에서 0.86 , flupyradifurone 0.12 에서 0.49 , isopyrazam 0.37 에서 0.55 , metrafenone 0.165 에서 0.4 , pyraclostrobin $<0.67$ 에서 1.17 , pinoxaden 0.48 에서 1.17 , sulfoxaflor 0.7 에서 1.3 , tebuconazole 0.27 에서 1 로 조사되었다. 농약 별로 각각 2.8배, 3.9배, 4.1배, 1.5배, 2.4배, 1.7 배, 2.4배, 1.9배, 3.7배로 평균 2.7배 증가하였다. 9종의 농 약은 휘발성이 낮고 지용성농약이며, 대부분 농약성분이 내부로 침투되는 특징으로 정맥을 침지시켜 발아시킨 후 물을 제거, 건 조되어 제조된 맥아에서 농약성분이 농축되는 것으로 판단된다. 보리의 대표적인 가공품인 맥주는 맥아를 이용하여 발효, 여과 과정을 거쳐 제조된다. 맥아를 맥주로 가공한 후 17 종 농약에 대한 PF는 맥아 0.1-1.3에서 0.001-0.67로 감소하였으며, 42.7$99.9 \%$ 의 감소율을 보였다[JMPR 2013, 2006, 2009, 2008, 2012, 2016, 2011]. 맥아에서 맥주로 가공하는 과정에서 PF는 평균 $82 \%$ 의 감소율을 나타냈다. 맥주의 발효과정 중 대부분의 농약 성분이 상당량 분해되거나 희석되는 것으로 판단되었다. $\mathrm{Im}$ 등의 연구[28]에서 JMPR에서 평가된 과일류 가공에 대한 농약의 가공계수 조사 결과, 포도주 가공에서 12 종 농약의 $\mathrm{PF}$ 가 평균 0.36 으로, $64 \%$ 감소되어, 포도주 발효과정 중 농약성 분이 분해됨을 알 수 있었다.

Zhiqiang 등의 연구[29]에서는 보리를 가공하여 triadimefon과 triadimenol의 잔류량을 분석하였다. 통보리는 $14,830,1,586 \mu \mathrm{g} /$ $\mathrm{kg}$ 으로 분석되었고, 맥아를 맥주로 가공할 때 잔류량은 12,950 및 $2,154 \mu \mathrm{g} / \mathrm{kg}$ 에서 254 및 $376 \mu \mathrm{g} / \mathrm{kg}$ 으로 감소하였다. 이 자료 를 이용하여 $\mathrm{PF}$ 를 산출하면, 맥아의 $\mathrm{PF}$ 는 0.87 과 1.36 , 맥주의
$\mathrm{PF}$ 는 0.017 과 0.24 이며, 맥아에서 맥주로 가공할 때 98 과 $82.4 \%$ 의 감소율을 보였다. 조사된 JMPR의 가공연구 결과와 유 사하게 맥아를 맥주 가공한 후 미량의 농약이 잔류되는 경향을 나타내었다.

통보리를 정맥으로 만드는 과정에서 ethephon, pyraclostrobin, penthiopyrad, sulfoxaflor 4종 농약의 잔류량에 대한 PF는 통보 리 1 에서 정맥은 농약 별로 각각 $0.1,<0.67,0.68,0.7$ 로 10 , 33,32 및 $30 \%$ 감소되었다. Ethephon은 $<0.01 \mathrm{mPa}\left(20^{\circ} \mathrm{C}\right)$ 와 $\mathrm{Kow}$ 가 $<-2.2$ 인 비휘발성, 수용성 농약으로 침투성을 가진 농 약으로 농약성분이 내부로 침투되어 탈피를 하여도 $10 \%$ 의 낮 은 감소율을 보이며 농약의 상당량이 제거되지 않는 것으로 나 타났다. Pyraclostrobin, penthiopyrad, sulfoxaflor는 $2.6 \times 10^{-5}$ $\left(20^{\circ} \mathrm{C}\right), 0.00643\left(25^{\circ} \mathrm{C}\right),<1.4 \times 10^{-6} \mathrm{mPa}$, Kow 3.99, 0.802 로 휘발성이 낮고 지용성의 특징을 가지며 침투성 농약으로 탈피 과정에서 약 $31 \%$ 정도 감소되었다.

Trinexapac-ethyl은 통보리를 정맥으로 만드는 과정에서 PF가 1 에서 1.2 로 되어 농약이 거의 제거되지 않았다. Trinexapacethyl은 증기압이 $2.16 \mathrm{mPa}\left(25^{\circ} \mathrm{C}\right)$ 이고 $\mathrm{Kow}$ 가 $-2.1(\mathrm{pH} 8.9)$, -0.29 ( $\mathrm{pH}$ 6.9), 1.5 (pH 5)으로 휘발성, 수용성 농약으로 조사 되었으나, 침투이행성 여부는 조사되지 않았다. 이 농약은 처리 과정에서 내부로 침투되어 껍질 제거 후에도 농약이 감소되지 않은 것으로 생각된다.

총 23종 중 boscalid, bixafen, benzovindiflupyr, fluxapyroxad 등 11종은 통보리를 탈피하며 정맥으로 만드는 과정에서 대부 분의 농약성분이 감소되었으나, 정맥을 침지시켜 만든 맥아의 경우 농약성분이 농축되었다. 그러나, 맥아를 맥주로 가공한 후 에는 대부분의 농약이 감소되어 미량의 성분만 잔류하는 경향 을 보였다. 침투성 농약인 ethephon, pyraclostrobin, penthiopyrad, sulfoxaflor 4종 농약은 농약성분이 보리 내부로 이행되어 정맥 으로 가공하는 과정 중에 많은 양이 제거되지 않았다. Trinexapac-ethyl 농약 또한 정맥으로 가공 후 농약이 농축되는 것으로 나타났다. 그러나 이들 농약이 처리된 정맥을 이후 다 른 가공 공정에서는 농약성분이 대부분 감소하는 경향으로 조 사되었다.

결론적으로 쌀과 보리에 살포된 35종 농약 중 8종(Acephate, methamidophos, glufosinate, guinclorac, sulfoxaflor, ethephon, pyraclostrobin, penthiopyrad) 은 지용성으로 물에 잘 녹지 않는 특성이며, 휘발성으로 가열처리에 의해 잘 감소되고, 침투성으 로 도정 후에도 가공계수가 낮아지지 않는 일반적인 경향을 보 이지만, 8종을 제외한 27종 농약(azoxystrobin, bentazone, benzovindiflupyr, bixafen, boscalid, chlorantraniliprole, chlorpyrifos-methyl, cyhalothrin, cypermethrin, dichlorvos, difenoconazole, dinotefuran, fenitrothion, flupyradifurone, flusilazole, fluxapyroxad, isopyrazam, metrafenone, picoxystrobin, pinoxaden, propiconazole, quinoxyfen, saflufenacil, tebuconazole, thiamethoxam, triazophos, trinexapac-ethyl)은 물리화학적 특성에 따라 가공계수가 변화되 는 일반적인 경향을 보이지 않았다.

\section{초 록}

본 연구에서는 2006년부터 2016년까지 JMPR보고서 중 쌀과 
보리의 농약 가공계수 자료를 고찰하였다. 쌀은 정조를 현미, 백미, 왕겨, 쌀겨 및 쌀밥으로 가공할 때 17종 농약의 가공계수 를 비교하였다. 17종 중 acephate, methamidophos, glufosinate, quinclorac과 sulfoxaflor 5종 농약을 제외한 12 종은 정조를 현 미로 가공할 때 대부분의 농약이 감소하였고, 현미에서 백미로 가공할 때 농약이 일부 감소하는 경향을 보였으며, 도정과정 중 발생된 왕겨와 쌀겨는 농약이 농축되었다. Acephate 등 5종 농 약은 침투성 농약으로 농약이 식품 내부로 침투되어 도정공정 중에 많은 양이 제거되지 않는 것으로 나타났다. 백미에 잔류 된 농약은 물과 함께 가열하여 쌀밥으로 가공한 후 대부분 제 거되어 농약 성분이 미량 잔류되었다. 보리는 통보리, 정맥, 분 말, short, 맥아, 맥주, 겉껍질 및 겨로 가공 중 23종 농약의 가 공계수를 비교하였다. 침투성 농약인 ethephon, pyraclostrobin, penthiopyrad, sulfoxaflor 4종을 제외한 농약은 통보리를 탈피하 여 정맥으로 만드는 과정에서 대부분의 농약 성분이 감소하였 다. 정맥을 침지시켜 만든 맥아의 경우 농약성분이 농축되었으 나, 맥주로 가공할 경우에는 대부분 분해되어 미량의 농약만 잔 류하는 경향을 보였다.

Keywords 가공계수 · 곡류가공 - 국제식품규격위원회 · 농약잔 류허용기준 · 잔류농약

감사의 글 이 논문은 2015년도 대구대학교 학술연구비 지원에 의하여 수행 되었습니다.

\section{References}

1. Chung HW, Ha YG, Im MH, Shin JE, Do JA, Oh JH, Cho JH, Kwon KS, Park SH (2011) Establishment of 22 pesticide MRLs in agricultural products based on risk assessment. Korean J Environ Agric 30: 166-172

2. Lee JK, Woo HD (2010) Current status for management of pesticide maximum residue limits in foods. Korean J Food Sci Technol 43: 2-23

3. FAO, WHO (2015) CODEX alimentarius commission procedural manual. Food and Agriculture Organization, World Health Organization, Rome

4. MFDS (2018) Food standard and specification. Ministry of Food and Drug Safety, Cheongju, Korea 35-36: 494-503

5. Im MH, Ji YJ (2016) A review on processing factors of pesticide residues during fruits processing. J Appl Biol Chem 53(3): 189-201

6. Park SY, Park KS, Im MH, Choi H, Chang MI, Kwon CH, Kim SG, Lee HK, Hong MK, Shim JH, Kim JH (2009) Studies for the processing factors of pesticides during the milling of wheat grain. Korean J Pest Sci 13: 70-78

7. Park SY, Kang HR, Ko KY, Gil KH, Im MH, Lee KS (2009) On the processing and reduction factors of several pesticides with welsh onion. Korean J Pest Sci 13: 249-255

8. Noh HH, Lee JY, Park SH, Lee KH, Oh JH, Im MH, Kyung KS (2012) Residual characteristics of azoxystrobin and difenoconazole in ginseng. Korean J Pest Sci 16: 131-136

9. Kim JG, Kim SS, Park HR, Ji KY, Lee KH, Ham HJ, Im MH, Hur JH (2009) Residues of azoxystrobin during cultivation and processing of ginseng. Korean J Pest Sci 13: 232-240

10. Noh HH, Lee KH, Lee JY, Lee EY, Park YS, Park HK, Oh JH, Im MH, Lee YJ, Baeg IH, Kyung KS (2012) Residual characteristics and processing factors of difenoconazole in Fresh ginseng and processed ginseng products. Korean J Pest Sci 16: 35-42

11. Lee JY, Noh HH, Lee KH, Park HK, Oh JH, Im MH, Kwon CH, Lee JK, Woo HD, Kwon KS, Kyung KS (2012) Processing factors of azoxystrobin in processed ginseng products. Korean J Pest Sci 16: 222 229

12. Lee EY, Noh HH, Park YS, Kang KW, Lee KH, Park HK, Kwon CH, Im MH, Kyung KS (2009) Processing and reduction factors of pesticide residues in chinese matrimony vine and jujube by drying. Korean J Pest Sci 13: $159-164$

13. Im MH, Kwon KI, Park KS, Choi DM, Chang MI, Jeong JY, Lee KJ, Yun MK, Hong MK, Woo GJ (2006) Study on reduction factors of residual pesticides in processing of ginseng. Korean J Pest Sci 10: 22-27

14. Im MH, Kwon KI, Park KS, Lee KJ, Chang MI, Yun WK, Choi WJ, Yoo KS, Hong MK (2007) Reduction rate of azoxystrobin, fenhexamid and cyprodinil during ginseng processing. Korean J Food Sci Technol 39: $575-579$

15. Park KS, Choi JH, Suh JH, Kim SG, Lee HK, Shim JH (2009) Studies on the Processing Factors of Pesticides in Dried Carrot from Field Trial and Dipping Test. Korean J Pest Sci 13(4): 209-215

16. Noh HH, Kang KW, Park HK, Lee KH, Lee JY, Lee EY, Park YS, Kyung KS (2010) Processing and Reduction Factors of Azoxystrobin and Flutolanil in Garlic by Freeze-Drying. Korean J Pest Sci 14(3): 235240

17. MFDS (2018) Korean Food Standards Codex. Pesticide MRLs. Ministry of Food and Drug Safety, http://www.foodsafetykorea.go.kr/foodcode/ index.jsp

18. FAO (2009) Submission and evaluation of pesticide residues data for the estimation of maximum residue levels in food and feed. Food and Agriculture Organization of The United Nations, Rome

19. FAO (2016) Submission and evaluation of pesticide residues data for the estimation of maximum residue levels in food and feed. Food and Agriculture Organization of The United Nations, Rome

20. Turner JA (2015) The Pesticide Manual A World Compendium Seventeenth Edition. BCPC, Alton, Hampshire UK

21. Umran Uygun, Hamit Koksel, Ayhan Ati (2005) Residue levels of malathion and its metabolites and fenitrothion in post-harvest treated wheat during storage, milling and baking. Food Chemistry 92, 643-647

22. Zhiqiang Kong, Fengshou Dong, Jun Xu, Xingang Liu, Jing Li, Yuanbo $\mathrm{Li}$ et al. (2012) Degradation of acephate and its metabolite methamidophos in rice during processing and storage. Food Control 23, $149-153$

23. Zhiqiang Kong, Minmin Li, Jieying Chen, Yuejing Gui, Yuming Bao, Bei Fan et al. (2016) Behavior of field-applied triadimefon, malathion, dichlorvos, and their main metabolites during barley storage and beer processing. Food Chemistry 211, 679-686

24. Umran Uygun, Recep Ozkara, Ayse Ozbey, Hamit Koksel (2007) Residue levels of malathion and fenitrothion and their metabolites in postharvest treated barley during storage and malting. Food Chemistry $100,1165-1169$

25. Park WJ, Lee SK, Kang YH, Kim JK, Yoon KS, Lee JM et al. (2015) FOOD PROCESSING. In Rice processing, pp. 129-134, Soohaksa, Seoul, Korea

26. Oh MJ, Son JR, Jung JH, Geum JH, Lee GS, Oh JS et al. (2007) Agricultural Food Processing. In Barley, pp. 85-93, SunJinMunhwasa, Goyang, Korea

27. Yang Mi Ok, Cho Eun Ja (1995) The Effect of Milling on the Nutrients Raw and Parboiled Rices. Korean J Soc Food Sci 11(1): 51-57

28. Im MH, Ji YJ (2016) A review on processing factors of pesticide residues during fruits processing. J Appl Biol Chem 59(3), 189-201

29. Zhiqiang Kong, Minmin Li, Jieying Chen, Yuming Bao, Bei Fan, Frederic Francis et al. (2016) Processing factors of triadimefon and triadimenol in barley brewing based on response surface methodology. Food Control 64, 81-86

30. 'Parboiled rice enhances rice processing industry's competitiveness', Food news, 2014.11.13, www.foodnesw.co.kr/news/articleView.html? idxno $=52875 .(2019.02 .20)$

31. Su-Rae Lee, Charles R. Mourer, Takayuki Shibamoto (1991) Analysis before and after Cooking Processes of a Trace Chlorpyrifos Spiked in 
Polished Rice. J Agric Food Chem. 39: 906-908

32. Zhibo Huan, Zhi Xu, Wayne Jiang, Zhiqiang Chen, Jinhui Luo (2015) Effect of Chinese traditional cooking on eight pesiticides residue during cowpea processing. Food Chemistry 170: 118-122

33. Park SY, Park KS, Im MH, Choi Hoon, Chang MI, Kwon CH et al. (2009) Studies for the Processing Factors of Pesticides during the Miling of Wheat Grain. Korean J Pest Sci 13(2): 70-78

34. JMPR (2006) Evaluation 2006-Pesticide residues in food 2006: 159-299 (boscalid). Joint Meeting of the FAO Panel of Experts on Pesticide Residues, Rome

35. JMPR (2006) Evaluation 2006-Pesticide residues in food 2006: 867-974 (quinoxyfen). Joint Meeting of the FAO Panel of Experts on Pesticide Residues, Rome

36. JMPR (2007) Evaluation 2007-Pesticide residues in food 2007: 607-617 (fenitrothion). Joint Meeting of the FAO Panel of Experts on Pesticide Residues, Rome

37. JMPR (2007) Evaluation 2007-Pesticide residues in food 2007: 619-772 (flusilazole). Joint Meeting of the FAO Panel of Experts on Pesticide Residues, Rome

38. JMPR (2007) Evaluation 2007-Pesticide residues in food 2007: 787-918 (propiconazole). Joint Meeting of the FAO Panel of Experts on Pesticide Residues, Rome

39. JMPR (2008) Evaluation 2008-Pesticide residues in food 2008: 1-202 (azoxystrobin). Joint Meeting of the FAO Panel of Experts on Pesticide Residues, Rome

40. JMPR (2008) Evaluation 2008-Pesticide residues in food 2008: 549-783 (cyhalothrin). Joint Meeting of the FAO Panel of Experts on Pesticide Residues, Rome

41. JMPR (2008) Evaluation 2008-Pesticide residues in food 2008: 785-890 (cypermethrin). Joint Meeting of the FAO Panel of Experts on Pesticide Residues, Rome

42. JMPR (2009) Evaluation 2009-Pesticide residues in food 2009: 147-262 (chlorpyrifos-methyl). Joint Meeting of the FAO Panel of Experts on Pesticide Residues, Rome

43. JMPR (2010) Evaluation 2010-Pesticide residues in food 2010: 17872021 (thiamethoxam). Joint Meeting of the FAO Panel of Experts on Pesticide Residues, Rome

44. JMPR (2011) Evaluation 2011-Pesticide residues in food 2011: 1-26 (acephate, methamidophos). Joint Meeting of the FAO Panel of Experts on Pesticide Residues, Rome

45. JMPR (2011) Evaluation 2011-Pesticide residues in food 2011: 727-871 (isopyrazam). Joint Meeting of the FAO Panel of Experts on Pesticide Residues, Rome

46. JMPR (2011) Evaluation 2011-Pesticide residues in food 2011: 9051088 (pyraclostrobin). Joint Meeting of the FAO Panel of Experts on Pesticide Residues, Rome

47. JMPR (2011) Evaluation 2011-Pesticide residues in food 2011: 12711417 (sulfoxaflor). Joint Meeting of the FAO Panel of Experts on Pesticide Residues, Rome

48. JMPR (2011) Evaluation 2011-Pesticide residues in food 2011: 14191613 (tebuconazole). Joint Meeting of the FAO Panel of Experts on Pesticide Residues, Rome

49. JMPR (2012) Evaluation 2012-Pesticide residues in food 2012: 413-464 (dichlorvos). Joint Meeting of the FAO Panel of Experts on Pesticide Residues, Rome

50. JMPR (2012) Evaluation 2012-Pesticide residues in food 2012: 477-590 (dinotefuran). Joint Meeting of the FAO Panel of Experts on Pesticide Residues, Rome

51. JMPR (2012) Evaluation 2012-Pesticide residues in food 2012: 659-935 (fluxapyroxad). Joint Meeting of the FAO Panel of Experts on Pesticide Residues, Rome
52. JMPR (2012) Evaluation 2012-Pesticide residues in food 2012: 9371182 (glufosinate). Joint Meeting of the FAO Panel of Experts on Pesticide Residues, Rome

53. JMPR (2012) Evaluation 2012-Pesticide residues in food 2012: 16591825 (picoxystrobin). Joint Meeting of the FAO Panel of Experts on Pesticide Residues, Rome

54. JMPR (2013) Evaluation 2013-Pesticide residues in food 2013: 1-36 (azoxystrobin). Joint Meeting of the FAO Panel of Experts on Pesticide Residues, Rome

55. JMPR (2013) Evaluation 2013-Pesticide residues in food 2013: 37-196 (bentazone). Joint Meeting of the FAO Panel of Experts on Pesticide Residues, Rome

56. JMPR (2013) Evaluation 2013-Pesticide residues in food 2013: 197-330 (bixafen). Joint Meeting of the FAO Panel of Experts on Pesticide Residues, Rome

57. JMPR (2013) Evaluation 2013-Pesticide residues in food 2013: 331-356 (chlorantraniliprole). Joint Meeting of the FAO Panel of Experts on Pesticide Residues, Rome

58. JMPR (2013) Evaluation 2013-Pesticide residues in food 2013: 357-360 (chlorpyrifos-methyl). Joint Meeting of the FAO Panel of Experts on Pesticide Residues, Rome

59. JMPR (2013) Evaluation 2013-Pesticide residues in food 2013: 13431360 (penthiopyrad). Joint Meeting of the FAO Panel of Experts on Pesticide Residues, Rome

60. JMPR (2013) Evaluation 2013-Pesticide residues in food 2013: 14991506 (triazophos). Joint Meeting of the FAO Panel of Experts on Pesticide Residues, Rome

61. JMPR (2013) Evaluation 2013-Pesticide residues in food 2013: 15951716 (trinexapac-ethyl). Joint Meeting of the FAO Panel of Experts on Pesticide Residues, Rome

62. JMPR (2015) Evaluation 2015-Pesticide residues in food 2015: 547-580 (difenoconazole). Joint Meeting of the FAO Panel of Experts on Pesticide Residues, Rome

63. JMPR (2015) Evaluation 2015-Pesticide residues in food 2015: 581-730 (ethephon). Joint Meeting of the FAO Panel of Experts on Pesticide Residues, Rome

64. JMPR (2015) Evaluation 2015-Pesticide residues in food 2015: 14411530 (quinclorac). Joint Meeting of the FAO Panel of Experts on Pesticide Residues, Rome

65. JMPR (2016) Evaluation 2016-Pesticide residues in food 2016: 145-256 (benzovindiflupyr). Joint Meeting of the FAO Panel of Experts on Pesticide Residues, Rome

66. JMPR (2016) Evaluation 2016-Pesticide residues in food 2016: 10551416 (flupyradifurone). Joint Meeting of the FAO Panel of Experts on Pesticide Residues, Rome

67. JMPR (2016) Evaluation 2016-Pesticide residues in food 2016: 16231648 (metrafenone). Joint Meeting of the FAO Panel of Experts on Pesticide Residues, Rome

68. JMPR (2016) Evaluation 2016-Pesticide residues in food 2016: 19012036 (pinoxaden). Joint Meeting of the FAO Panel of Experts on Pesticide Residues, Rome

69. JMPR (2016) Evaluation 2016-Pesticide residues in food 2016: 20372082 (saflufenacil). Joint Meeting of the FAO Panel of Experts on Pesticide Residues, Rome

70. JMPR (2016) Evaluation 2016-Pesticide residues in food 2016: 22612292 (sulfoxaflor). Joint Meeting of the FAO Panel of Experts on Pesticide Residues, Rome

71. Buggenhout J, Brijs K, Celus I, Delcour JA (2013) The breakage susceptibility of raw and parboiled rice: A review. Journal of Food Engineering 117: 304-315 